\section{Isolation, molecular identification and antimicrobial resistance patterns of Campylobacter species of dairy origin: First report from Bangladesh}

\author{
S. M. Lutful Kabir, ${ }^{1}$ Most. Mostary \\ Lubna, ${ }^{1}$ Md. Mehedul Islam, 1
}

A. K. M. Ziaul Haque, 1

Sucharit Basu Neogi,2 Shinji Yamasaki²

1Department of Microbiology and

Hygiene, Bangladesh Agricultural

University, Mymensingh, Bangladesh;

${ }^{2}$ Graduate School of Life and

Environmental Sciences, Osaka

Prefecture University, Osaka, Japan

\begin{abstract}
This study was aimed for isolation, identification and characterization of Campylobacter species from Bangladesh Agricultural University dairy farm during the period of January to May, 2016. A total of 80 samples (fecal samples of calves, heifers and cows; milk samples of cows) were collected from Bangladesh Agricultural University dairy farm for isolation and identification of Campylobacter species by using cultural, biochemical and molecular methods. Moreover, the isolated Campylobacter species were subjected for antimicrobial susceptibility test. Campylobacter like organisms were presumptively identified in 20 samples. Isolates were biochemically positive to catalase and oxidase tests and in hippurate hydrolysis test some of the isolates $(n=6)$ shown negative that indicated the isolates were $C$. coli and some of the test isolates $(\mathrm{n}=14)$ shown positive that indicated the isolates were $C$. jejuni. Campylobacter specific $16 \mathrm{~S}$ rRNA genes were amplified from the isolates. Out of 20 isolated Campylobacter 14 $(17.5 \%)$ were detected as $C$. jejuni and the rest $6(7.5 \%)$ were detected as $C$. coli by $c d t C$ gene based multiplex PCR assay. $C$. jejuni were resistant to amoxicillin, erythromycin, azithromycin and susceptible to gentamicin, ciprofloxacin, norfloxacin and streptomycin. Furthermore, $C$. coli were resistant to amoxicillin and erythromycin and susceptible to gentamycin, ciproflaxacin. Out of 20 Campylobacter isolates, $57.14 \%$ C. jejuni and $33.33 \%$ C. coli were identified as multidrug resistant. To the best of our knowledge, this study has brought the first report on the occurrence of Campylobacter species with their antibiogram profiles in any dairy farm of Bangladesh.
\end{abstract}

\section{Introduction}

Campylobacter spp. are Gram negative, microaerophilic bacteria with slightly curved or spiral rods shaped under the family of Campylobacteriaceae. ${ }^{1}$ At least a dozen of Campylobacter spp. has been associated with human disease and the most common are $C$. jejuni and $C$. coli. ${ }^{2}$ Development of human infection may occur by direct contact with infected animals or by consumption of contaminated unpasteurized milk or milk products, contaminated water and raw meat and domestic birds are considered as important reservoirs of foodborne infection for humans. ${ }^{3}$ The importance of milk for the development of human gastroenteritis due to Campylobacter spp. was confirmed by the summary report of European Union on food-borne disease outbreaks. ${ }^{4}$ It is assumed that contamination of raw milk by Campylobacter spp. derived from secondary fecal contamination during the milking process. ${ }^{5}$ The infection has been developed due to consumption of raw milk that is the most important source of Campylobacter ${ }^{6}$ Longer life span of dairy cattle than beef cattle can serve as a longterm reservoir of Campylobacter spp. in dairy cattle.5,7 The development of environmental contamination through indirect exposure of cattle feces is considered a high risk to human infections. ${ }^{7}$ The ideal environment for optimal growth of Campylobacter spp. requires an atmosphere containing approximately $5 \% \mathrm{O}_{2}, 10 \%$ $\mathrm{CO}_{2}$, and $85 \% \mathrm{~N}_{2}$ at $37^{\circ} \mathrm{C}$ to $42^{\circ} \mathrm{C} .{ }^{8}$ The selective blood-containing agar are recommended medium that are used for culture of Campylobacter spp. ${ }^{8}$ although alternative media may be used. The viability of $C$. jeju$n i$ in faces and milk may remain for up to 9 days and 3 days respectively. ${ }^{9}$ Contamination of raw milk with Campylobacter spp. mainly associated with fecal contamination. ${ }^{10}$

The concerns for human health are the inappropriate use of antibiotics in cattle production and the development of antimicrobial resistant strains of bacteria. The increasing rate of human infections caused by antimicrobial-resistant Campylobacter spp. makes more difficult to clinical management of campylobacteriosis. ${ }^{11}$ Campylobacter spp. with resistant to antimicrobial agent has been reported worldwide. ${ }^{12-14}$

In Bangladesh several studies such as occurrence, molecular detection and antibiotic sensitivity test of Campylobacter spp. in poultry farms have been performed. ${ }^{14,15}$ However, there are no documented reports exist yet on the occurrence and antibiogram
Correspondence: S. M. Lutful Kabir, Department of Microbiology and Hygiene, Bangladesh Agricultural University, Mymensingh-2202, Bangladesh.

Phone: +88-091-67401-6/Ext. 63218.

E-mail: 1kabir79@gmail.com

Key words: Dairy farm; C. jejuni; C. coli; Molecular identification; Antibiogram profiles.

Acknowledgements: Authors gratefully acknowledge the support of Professor Dr. Shinji Yamasaki, Graduate School of Life and Environmental Sciences, Osaka Prefecture University, Osaka, Japan who provided us microaerophilic gas packs used in this research work.

Contributions: S. M. Lutful Kabir planned and designed the study. Most. Mostary Lubna and Md. Mehedul Islam assisted in data collection, laboratory work, data analysis and drafting of the manuscript. S. M. Lutful Kabir, A.K.M. Ziaul Haque, Sucharit Basu Neogi and Shinji Yamasaki assisted in data analysis and drafting of the manuscript.

Conflict of interest: the authors declare no potential conflict of interest.

Funding: part of this work was supported by grants from Bangladesh Agricultural University Research System (BAURES), Mymensingh, Bangladesh (Project No. 2015/102/BAU).

Received for publication: 20 August 2018 Accepted for publication: 9 January 2019.

This work is licensed under a Creative Commons Attribution NonCommercial 4.0 License (CC BY-NC 4.0).

CCopyright S. M. L. Kabir et al., 2018 Licensee PAGEPress srl, Italy

Veterinary Science Development 2018; 8:7838 doi:10.4081/vsd.2018.7838

profiles of Campylobacter spp. in dairy farm where milk is widely consumed in Bangladesh. Therefore, this study was aimed to isolate and identify Campylobacter spp. inhabiting feces and milk originating from Bangladesh Agricultural University dairy farm and to assess antibiogram profiles of the isolated Campylobacter spp.

\section{Materials and Methods}

\section{Collection, transportation and pro- cessing of samples}

A total of 80 samples (60 fecal samples 
and 20 milk samples) were collected from Bangladesh Agricultural University (BAU) dairy farm during the period of January to May, 2016. Then the collected samples were transferred to Molecular Bacteriology Laboratory of the Department of Microbiology and Hygiene, Bangladesh Agricultural University, Mymensingh through thermos flask. Then the samples were processed immediately for the isolation and identification of Campylobacter species.

\section{Isolation of Campylobacter species}

Isolation of Campylobacter species were carried out by filtration method ( 0.45 $\mu \mathrm{m}$ filter; Biotech, Germany) as described by Shiramaru et al. 16

\section{Identification of Campylobacter spp. by biochemical tests}

Differentiation of isolated Campylobacter spp. were performed by various biochemical tests such as catalase, oxidase and hippurate hydrolysis test according to the methods described by Foster et al. ${ }^{17}$

\section{Preparation of DNA templates}

DNA templates were prepared by boiling method according to the procedures mentioned by Hoshino et al. 18

\section{S rRNA-gene-based PCR for identification of the genus Campylobacter}

The 16S rRNA gene was selected for the identification of the genus Campylobacter. Primers (Invitrogen, USA) used for the amplification of $16 \mathrm{~S}$
rRNA gene are shown in Table 1. The reaction mixture $(20 \mu \mathrm{L})$ was prepared by mixing $10 \mu \mathrm{L}$ master mixtures (Promega, USA), $1 \mu \mathrm{L}$ forward primer (10 pmol), $1 \mu \mathrm{L}$ reverse primer $(10 \mathrm{pmol}), 3 \mu \mathrm{L}$ DNA template and $5 \mu \mathrm{L}$ deionized water. The PCR reactions were carried out using a thermocycler (Astec, Japan) with the following program: initial denaturation with 1 cycle of 5 min at $94^{\circ} \mathrm{C}, 30$ cycles each consisting of denaturation with $30 \mathrm{~s}$ at $94^{\circ} \mathrm{C}$, annealing with $30 \mathrm{~s}$ at $47^{\circ} \mathrm{C}$, extension with $1 \mathrm{~min} 30 \mathrm{~s}$ at $72{ }^{\circ} \mathrm{C}$ and a final extension step of $10 \mathrm{~min}$ at $72^{\circ} \mathrm{C}$. PCR products were analyzed by $1.5 \%$ agarose (Invitrogen, USA) gel electrophoresis and the bands were visualized with UV light after staining with ethidium bromide $(0.5 \mu \mathrm{g} / \mathrm{mL})$ for 10 minutes in a dark place. Bands were visualized and images were captured on a UV transilluminator (Biometra, Germany).

\section{cdtC gene based PCR for species identification}

$c d t C$ gene based multiplex PCR was used for the species identification of C. jeju$n i$ and $C$. coli as described by Asakura et al. ${ }^{19}$ The primers (Bioneer, South Korea) used for the $c d t C$ gene based PCR multiplex PCR are shown in Table 1.19-22 The reaction mixture $(20 \mu \mathrm{L})$ was prepared by mixing 10 $\mu \mathrm{L}$ master mixtures (Promega, USA), $1 \mu \mathrm{L}$ forward primer (10 pmol), $1 \mu \mathrm{L}$ reverse primer (10 pmol), $3 \mu \mathrm{L}$ DNA template and 5 $\mu \mathrm{L}$ deionised water. The PCR reactions were carried out using a thermocycler (Astec, Japan) with the following program: initial denaturation with 1 cycle of $5 \mathrm{~min}$ at $94^{\circ} \mathrm{C}$, 30 cycles each consisting of denaturation with $30 \mathrm{~s}$ at $94^{\circ} \mathrm{C}$, annealing with $30 \mathrm{~s}$ at $55^{\circ} \mathrm{C}$, extension with $30 \mathrm{~s}$ at $72^{\circ} \mathrm{C}$ and a final extension step of $5 \mathrm{~min}$ at $72^{\circ} \mathrm{C}$. PCR products were analyzed by $2 \%$ agarose (Invitrogen, USA) gel electrophoresis. Bands were visualized and images captured as described above.

\section{Antimicrobial susceptibility test}

All Campylobacter spp. were tested against eight commonly used antibiotics (HiMedia, India) by the method of disk diffusion as described by Luangtongkum et $a l .{ }^{20}$ The zones of growth inhibition were compared with the zone size interpretative standards as described by Clinical and Laboratory Standard Institute. ${ }^{21} E$. coli ATCC 25922 was kept as a quality control bacterium in this study. At least two separate experiments were performed for confirmation of all susceptibility data.

\section{Results}

\section{Isolation and identification of} Campylobacter species using conven-

\section{tional methods}

The occurrences of Campylobacter species available in fecal and milk samples are shown in Table 2. A total of 80 samples [fecal (60) and milk (20)] were subjected for isolation of Campylobacter strains by filtration method. Campylobacter spp. produced grey color spreading colonies on Blood agar base no. 2 media after 48 hrs of incubation at $37^{\circ} \mathrm{C}$ using microaerophilic condition $\left(5 \% \mathrm{O}_{2}, 10 \% \mathrm{CO}_{2}\right.$ and $\left.85 \% \mathrm{~N}_{2}\right)$. In Gram's staining examination, the organism shown Gram negative, pink color, small

Table 1. Primers used for the various PCR.

\begin{tabular}{|c|c|c|c|c|}
\hline Primer & Sequence $\left(5^{\prime}-3^{\prime}\right)$ & Target & Amplicon size (bp) & Reference \\
\hline $\begin{array}{l}16 \mathrm{~S} 9 \mathrm{~F} \\
16 \mathrm{~S} 1540 \mathrm{R}\end{array}$ & $\begin{array}{l}\text { GAGTTTGATCCTGGCTC } \\
\text { AAGGAGGTGATCCAGCC }\end{array}$ & 16S rRNA gene & 1530 & [22] \\
\hline $\begin{array}{l}\text { Cj-cdtCU1 } \\
\text { Cj-CdtCR2 }\end{array}$ & $\begin{array}{l}\text { TTTAGCCTTTGCAACTCCTA } \\
\text { AAGGGGTAGCAGCTGTTAA }\end{array}$ & Cj-cdtC & 524 & [19] \\
\hline $\begin{array}{l}\text { Cc-CdtCU1 } \\
\text { Cc-CdtCR1 }\end{array}$ & $\begin{array}{l}\text { TAGGGATATGCACGCAAAG } \\
\text { GCTTAATACAGTTACGATAG }\end{array}$ & Cc-cdtC & 313 & [19] \\
\hline $\begin{array}{l}\text { CfspCU2 } \\
\text { CfspCR1 }\end{array}$ & $\begin{array}{l}\text { AAGCATAAGTTTTGCAAACG } \\
\text { GTTTGGATTTTCAAATGTTCC }\end{array}$ & Cf-cdtC & 397 & [19] \\
\hline
\end{tabular}

Table 2. Percentages (\%) of Campylobacter species available in fecal and milk samples.

\begin{tabular}{llcccc} 
Types of sample & Species & No. of sample & $\begin{array}{c}\text { No. (\%) of Campylobacter isolates } \\
\text { C. colt }\end{array}$ & $\begin{array}{c}\text { Overall no. (\%) } \\
\text { of Campylobacter species }\end{array}$ \\
Faecal & Calves & 20 & $2(10)$ & $0(0)$ & $20(25)$ \\
& Heifers & 20 & $5(20)$ & $2(10)$ & $20(25)$ \\
Milk & Cows & 20 & $3(25)$ & $3(15)$ & $1(5)$ \\
\hline Total & Cows & 20 & $14(17)$ & $6(7.5)$ & $20(25)$ \\
\hline
\end{tabular}


curved shape arranged as single or in pair under microscope $(100 \mathrm{X})$. Out of $60 \mathrm{fecal}$ samples only $16(26.66 \%)$ were positive for Campylobacter spp. and out of 20 milk samples, $4(20 \%)$ were positive for Campylobacter spp. Campylobacter like organisms were then subjected for biochemical tests. All the isolates of Campylobacter spp. $(\mathrm{n}=20)$ produced bubbles were found positive in catalase test. All the isolates of Campylobacter spp. $(n=20)$ produced deep blue color within 10 seconds were found positive in oxidase test. In hippurate hydrolysis test some of the isolates $(n=6)$ did not develop any purple color that indicated the isolates were C. coli and some of the test isolates $(n=14)$ developed purple color that indicated the isolates were $C$. jejuni.

\section{Molecular identification of Campylobacter spp.}

Genus specific PCR with the gene of 16S rRNA was performed. $1530 \mathrm{bp}$ frag- ment of targeted gene was amplified successfully (Figure 1). The multiplex PCR assay targeting the $c d t C$ gene was used and $14 C$. jejuni gave specific amplification (524 bp) (Figure 2). Similarly, $6 C$. coli gave specific amplification (313 bp) by multiplex PCR assay targeting $c d t C$ gene (Figure 3). None of the tested strains produced a specific band corresponding to the gene of $c d t C$ of $C$. fetus (data not shown).

\section{Antibiogram profiles of isolated Campylobacter spp.}

14 isolates of $C$. jejuni were subjected to antimicrobial susceptibility testing against 8 selected antibiotics (Table 3). Among all the isolates $10(71.42 \%)$ were susceptible to gentamicin, $4(28.57 \%)$ were susceptible to norfloxacin, 4 (28.57\%) were susceptible to ciprofloxacin, 5 (35.71\%) were susceptible to streptomycin and 1 $(7.14 \%)$ was susceptible to azithromycin. All data of antibiogram profile shown that the isolates were resistant to amoxicillin 12 $(85.71 \%)$, tetracycline $12 \quad(85.71 \%)$, azithromycin 12 (85.71\%), erythromycin 14 (100\%). Furthermore, 8 (57.14\%) were resistant to streptomycin, $7(50 \%)$ were resistant to norfloxacin, $2(14.28 \%)$ were resistant to gentamicin and $4(28.57 \%)$ were resistant to ciprofloxacin. $6(42.85 \%)$ isolates were intermediate resistant to ciprofloxacin, $3(21.42 \%)$ were intermediate resistant to norfloxacin, 1 (7.14) was intermediate resistant to streptomycin, 2 (14.28) were intermediate resistant to amoxicillin. Six isolates of $C$. coli were subjected to antimicrobial susceptibility testing against 8 selected antibiotics (Table 4). Among all the isolates $4(66.67 \%)$ were susceptible to gentamicin, $3(50 \%)$ were susceptible to ciprofloxacin, 1 (16.67) was susceptible to norfloxacin, 1 (16.67) was susceptible to azithromycin, 2 (33.33\%) were susceptible to streptomycin. Antibiogram profiles revealed that the isolates were resistant to amoxicillin 4

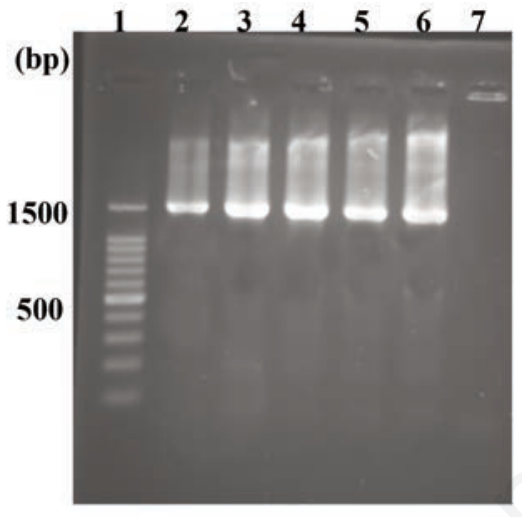

Figure 1. Detection of Campylobacter spp. by $16 S$ rRNA gene based PCR. Lanes: 1, 100 bp DNA ladder (Promega, USA); 7, negative control; 2-6, tested positive samples.

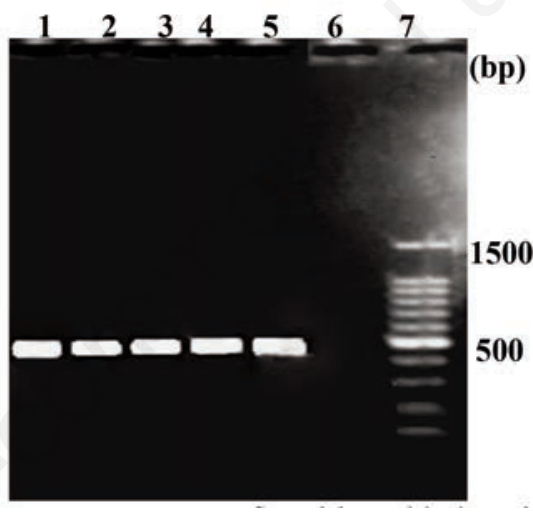

Figure 2. Detection of Campylobacter jeju$n i$ by $c d t C$ gene based multiplex PCR assay. Lanes: 1-5, tested positive samples; 6, negative control; 7, 100 bp DNA ladder (Promega, USA).

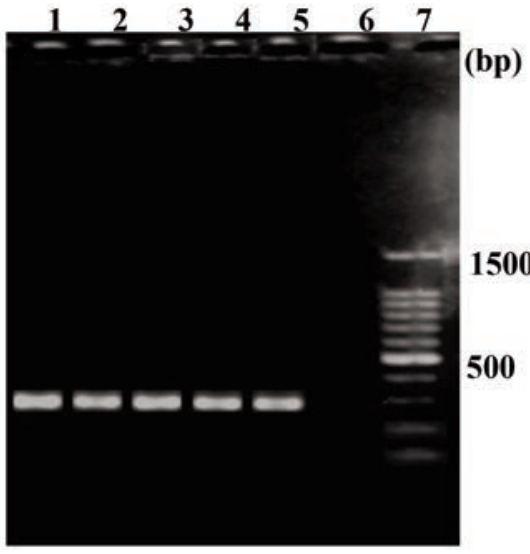

Figure 3. Detection of Campylobacter coli by $c d t$ C gene based multiplex PCR assay. Lanes: 1-5, tested positive samples; 6, negative control; 7, 100 bp DNA ladder (Promega, USA).

Table 3. Antimicrobial susceptibility pattern of $C$. jejuni $(n=14)$ identified by the disk diffusion method.

\begin{tabular}{lccc} 
Antimicrobial agents & S $(\%)$ & Number (\%) of C. jejuni & R (\%) \\
Amoxicillin & $0(0)$ & $2(14.28)$ & $12(85.71)$ \\
Tetracycline & $0(0)$ & $2(14.28)$ & $12(85.71)$ \\
\hline Gentamicin & $10(71.42)$ & $2(14.28)$ & $2(14.28)$ \\
Erythromycin & $0(0)$ & $0(0)$ & $14(100)$ \\
\hline Azithromycin & $1(7.14)$ & $1(7.14)$ & $12(85.71)$ \\
Ciprofloxacin & $4(28.57)$ & $6(42.85)$ & $4(28.57)$ \\
\hline Norfloxacin & $4(28.57)$ & $3(21.42))$ & $7(50)$ \\
Streptomycin & $5(35.71)$ & $1(7.14)$ & $8(57.14)$ \\
\hline
\end{tabular}

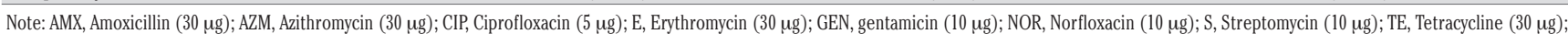
b: $\mathrm{S}=$ Susceptible; $\mathrm{I}=$ Intermediate resistance; $\mathrm{R}=$ Resistance. 
$(66.67 \%)$, tetracycline $4(66.67 \%)$, erythromycin $6(100 \%)$, streptomycin $3(50)$, norfloxacin $3(50 \%)$, azithromycin 3 (50), gentamicin 1 (16.67) and ciprofloxacin 1 (16.67). Moreover, 2 (33.33\%) were intermediate resistant to ciprofloxacin, 2 (33.33) were intermediate resistant to norfloxacin, 2 $(33.33 \%)$ were intermediate resistant to azithromycin, 2 (33.33) were intermediate resistant to tetracycline and $1(16.67 \%)$ was intermediate resistant to gentamicin. The result of resistance patterns of isolated $C$. jejuni and $C$. coli are shown in Table 5. Out of 14 C. jejuni isolates, $3(21.42 \%)$ was resistant to 1 agent (AMX), 2 (14.29) were resistant to 1 agent (E), 1 (7.14\%) was resistant to 1 agent (AZM). Furthermore, $1(7.14 \%)$ was resistant to 2 agents (AMXTE), 2(14.29) were resistant to 2 agents (AMX-S) respectively. Moreover, 1 (7.14\%) was resistant to 3 agents (AMX-STE), 2 (14.29) were resistant to 3 agents (ES-CIP), 1 (7.14\%) was resistant to 4 agent (AMX-NOR-AZM-TE) and 1 (7.14\%) was resistant to 5 agents (AMX-S-E-AZM-TE) respectively. Out of $6 \mathrm{C}$. coli isolates, 4 (66.67\%) were resistant to 1 agent (AMX), 1 (16.67) were resistant to 2 agent (AMXE) and 1 (16.67) was resistant to 3 agents (AMX-S-TE) respectively. In this study, multidrug resistant Campylobacter spp. were identified by considering resistant to 2 or more drugs as described in Table 5. A total of $14 C$. jejuni were isolated and 8 (57.14) were identified as multidrug resistant. Out of 6 C. coli 2 (33.33) were identified as multidrug resistant.

\section{Discussion}

To our knowledge, this study has brought the first report on investigating the prevalence of Campylobacter spp. in dairy farms of Bangladesh. Cultural examination, staining characteristics, biochemical tests and finally PCR were performed for the characterization of the Campylobacter spp. and the colony characteristics were exhibited grey color which was supported by several researchers. ${ }^{15,23}$ The routine isolation and identification of Campylobacter spp. in laboratories were conducted on the basis of cultural and biochemical methods which was supported by several researchers. ${ }^{24}$ Hippurate hydrolysis test was used for discriminating between $C$. jejuni and $C$. coli which was also used by several researchers. $13,15,16$ The current study recorded $16 \quad(26.66 \%)$ and $4 \quad(20 \%)$ Campylobacter spp. from 60 fecal and 20 milk samples respectively during the study period. Out of 80 samples, $14(17 \%)$ isolates were $C$. jejuni and the remaining 6 $(7.5 \%)$ isolates were $C$. coli. Ramonaite et al.24 also recorded Campylobacter jejuni and Campylobacter coli from dairy farm in Lithuania. PCR primers targeting 16S rRNA gene of Campylobacter spp. were amplified 1530 bp fragments of DNA confirmed the identity of Campylobacter spp. (Figure 1). All Campylobacter isolates were positive to $16 \mathrm{~S}$ rRNA gene based PCR which is supported by Kabir et al. ${ }^{13,14}$ The $c d t C$ gene was amplified for detecting and discriminating between $C j-c d t C$ and $C c$ $c d t C$ (Figures 2 and 3) likewise several researchers. ${ }^{13}$

Despite of the fact that Campylobacter spp. is common in dairy cattle, our study revealed a moderate rate of prevalence $(20 \%)$ in BAU dairy farm, Mymensingh, Bangladesh as shown in Table 2. Other researchers reported prevalence between 5\% and 78.5\%.25,26 Since sampling design, cultural methods and conditions were varied among these studies, a direct comparison of the results is troublesome. However, our data contribute to previous conversation that dairy cattle are significant assortment for Campylobacter spp. and could be a source of infections. The present study recorded that Campylobacter

Table 4. Antimicrobial susceptibility pattern of $C$. coli $(n=6)$ identified by the disk diffusion method.

\begin{tabular}{lccc} 
Antimicrobial agents & S $(\%)$ & Number of $\boldsymbol{C}$. coll isolates & R (\%) \\
Amoxicillin & $0(0)$ & $2(33.33)$ & $4(66.67)$ \\
Tetracycline & $0(0)$ & $2(14.28)$ & $4(66.67)$ \\
\hline Gentamicin & $4(66.67)$ & $1(16.67)$ & $1(16.67)$ \\
Erythromycin & $0(0)$ & $0(0)$ & $6(100)$ \\
\hline Azithromycin & $1(16.67)$ & $2(33.33)$ & $3(50)$ \\
Ciprofloxacin & $3(50)$ & $2(33.33)$ & $1(16.67)$ \\
\hline Norfloxacin & $1(16.67)$ & $2(33.33)$ & $3(50)$ \\
Streptomycin & $2(33.33)$ & $1(16.67)$ & $3(50)$
\end{tabular}

Table 5. Antimicrobial resistance pattern of $C$. jejuni and C. coli.

\begin{tabular}{llll} 
Species & Resistance patterns & No. of resistant isolates (\%) & No. of multidrug resistant isolates (\%) \\
C. jejuni $(\mathrm{n}=14)$ & No resistance demonstrated & $3(21.42)$ & 8 (57.14) \\
& Resistant to 1 agent (AMX) & $2(14.29)$ \\
& Resistant to 1 agent (E) & $1(7.14)$ \\
& Resistant to 1 agent (AZM) & $1(7.14)$ \\
& Resistant to 2 agents (AMX- TE) & $2(14.29)$ \\
& Resistant to 2 agents (AMX-S) & $1(7.14)$ \\
& Resistant to 3 agents (AMX-S-TE) & $2(14.29)$ \\
& Resistant to 3 agents (E-S-CIP) & $1(7.14)$ \\
& Resistant to 4 agents (AMX-NOR-AZM-TE) & $1(7.14)$ \\
& Resistant to 5 agents (AMX-S-E-AZM-TE) & $14(100)$ \\
& Total resistant isolates & $4(66.67)$ \\
C. coli $(\mathrm{n}=6)$ & Resistant to 1 agent (AMX) & $1(16.67)$ \\
& Resistant to 2 agents (AMX-E) & $1(16.67)$ \\
& Resistant to 3 agents (AMX-S-TE) & $6(100)$ \\
\hline
\end{tabular}


species may be found more frequently in fecal samples than milk samples.

In the antimicrobial susceptibility testing most of the isolates were susceptible to ciprofloxacin, gentamicin and all the isolates were resistant to amoxicillin, erythromycin. These findings are close to the findings of several researchers. ${ }^{27}$ The current study also recorded some multidrug resistant spp. in collected samples of BAU dairy farm. Out of 20 isolates, $57.14 \%$ C. jejuni and $33.33 \%$ C. coli were detected as multidrug resistant. Resistant profiles of multidrug resistant Campylobacter spp. were close to the result of some researchers. ${ }^{15,20}$ Findings of this study suggested that multidrug resistant Campylobacter spp. isolated from dairy farm might be an important concern for veterinary practitioners.

\section{Conclusions}

The findings of this study demonstrated the presence of multidrug resistant $C$. jejuni and $C$. coli in feces and milk samples that are not only harmful for cattle itself but also are harmful for consumers on milk consumption. Nevertheless, more studies are needed to clearly understand the genomic diversity in $C$. jejuni and $C$. coli as well as molecular mechanisms for the development of antimicrobial resistance.

\section{References}

1. Brenner DJ, Krieg NR. Bergey's Manual of Systematic Bacteriology. In: The Proteobacteria. Springer Science and Business Media 2006; pp 1147 1160 .

2. Ryan KJ, Ray C. Medical Microbiology. In: An introduction to infectious diseases, $4^{\text {th }} \mathrm{Ed}$, McgrawHill, 2004; 378-380.

3. Mezher Z, Saccares S, Marciano R, et al. Occurrence of Campylobacter species in poultry meat at retail and processing plants' levels in Central Italy. Ital J Food Saf 2016;5:47-9.

4. European Food Safety Authority. The European Union summary report on trends and sources of zoonoses, zoonotic agents and foodborne outbreaks in 2013, Vol 13. EFSA J 2015;13: 1-165.

5. Oliver SP, Jayarao BM, Almeida RA, et al. Food-borne pathogens in milk and the dairy farm environment: food safety and public health implications. Foodborne Pathog Dis 2005;2:115-29.
6. Heuvelink AE, Van HC, Zwartkruis NA, et al. Two outbreaks of campylobacteriosis associated with the consumption of raw cows' milk. Int J Food Microbiol 2009;134:70-4.

7. Devane ML, Nicol C, Ball A, et al. The occurrence of Campylobacter subtypes in environmental reservoirs and potential transmission routes. J Appl Microbiol 2005;98:980-90.

8. Corry JE, Atabay HI, Forsythe SJ, et al. Culture media for the isolation of Campylobacters, Helicobacters and Arcobacters. Prog Ind Microbiol 2003;37:271-316.

9. Silva J, Leite D, Fernandes M, et al. Campylobacter spp. as a food-borne pathogen: a review. Front Microbiol 2011;2:1-12.

10. Park SF. The physiology of Campylobacter spp. and its relevance to their role as food borne pathogens. Int $\mathrm{J}$ Food Microbiol 2002;74:177-88.

11. Levin RE. Campylobacter jejuni: a review of its characteristics, pathogenicity, ecology, distribution, subspecies characterization and molecular methods of detection. Food Biotechnol 2007;21:271-347.

12. Chen X, Naren GW, Wu CM, et al. Prevalence and antimicrobial resistance of Campylobacter isolates in broilers from China. Vet Microbiol 2010;144:133-9.

13. Kabir SML, Kikuchi K, Asakura M, et al. Evaluation of a cytolethal distending toxin (cdt) gene-based species-specific multiplex PCR assay for the identification of Campylobacter strains isolated from diarrheal patients in Japan. Jpn J Infect Dis 2011;64:19-27.

14. Kabir SML, Asakura M, Shiramaru S, et al. Molecular identification and antimicrobial resistance profiles of Campylobacter strains of poultry origin in India with special emphasis on fluoroquinolone resistance. Asian J Med Biol Res 2015;1:1-8.

15. Kabir SML, Sumon MH, Amin MM, et al. Isolation, identification and antimicrobial resistance patterns of Campylobacter Species from broiler meat sold at KR market of Bangladesh Agricultural University campus. J Agric Food Tech 2014;4:1-7.

16. Shiramaru S, Asakura M, Inoue $H$, et al. A cytolethal distending toxin genebased multiplex PCR assay for detection of Campylobacter spp. in stool specimens and comparison with culture method. J Vet Med Sci 2012;74:857-62.

17. Foster G, Holmes B, Steigerwalt AG, et al. Campylobacter insulaenigrae sp. nov., isolated from marine mammals. Int $\mathrm{J}$ Syst Evol Microbiol 2004;54:2369-73.

18. Hoshino K, Yamasaki S, Mukhopadhyay AK, et al. Development and evaluation of a multiplex PCR assay for rapid detection of toxigenic Vibrio cholerae O1 and O139. FEMS Immunol Med Microbiol 1998;20:2017.

19. Asakura M, Samosornsuk W, Hinenoya A, et al. Development of a cytolethal distending toxin (cdt) gene-based species-specific multiplex PCR assay for the detection and identification of Campylobacter jejuni, Campylobacter coli and Campylobacter fetus. FEMS Immunol Med Microbiol 2008;52:2606.

20. Luangtongkum T, Jeon B, Han J, et al. Antibiotic resistance in Campylobacter: emergence, transmission and persistence. Future Microbiol 2009;4:189200.

21. Clinical and Laboratory Standards Institute. Performance standards for antimicrobial susceptibility testing, twenty-fifth informational supplements, Vol 35, CLSI document M100-S25, 2015; 1-231.

22. Samosornsuk W, Hinenoya A, Misawa N, et al. Development of a cytolethal distending toxin (cdt) gene-based species-specific multiplex PCR assay for the detection and identification of Campylobacter jejuni, Campylobacter coli and Campylobacter fetus. FEMS Immunol Med Microbiol 2007;52:2606.

23. Doyle MP. Campylobacter jejuni, In: D.O. Cliver Ed, Academic Press, Food diseases Inc., Boston. 1990; 217-222.

24. Jamshidi A, Bassami MR, Farkhondeh T. Isolation and identification of Campylobacter spp. and Campylobacter coli from poultry carcasses by conventional culture method and multiplex PCR in Mashhad, Iran. Iran J Vet Res 2008;9:132-7.

25. Ramonaite S, Rokaityte A, Tamuleviciene E, et al. Prevalence, quantitative load and genetic diversity of Campylobacter spp. in dairy cattle herds in Lithuania. Acta Vet Scand 2013;55:1-6.

26. Sasaki Y, Murakami M, Haruna M, et al. Prevalence and characterization of food-borne pathogens in dairy cattle in the eastern part of Japan. J Vet Med Sci 2013;75:543-6.

27. Butzler JP. Campylobacter from obscurity to celebrity. Clin Microbiol Infect 2004;10:868-76. 